Check for updates

Cite this: RSC Adv., 2017, 7, 24547

Received 15th March 2017

Accepted 27th April 2017

DOI: $10.1039 / \mathrm{c} 7 \mathrm{ra03069j}$

rsc.li/rsc-advances

\section{Asymmetric Michael addition reactions of pyrrolones with chalcones catalyzed by vicinal primary-diamine salts $\uparrow$}

\author{
Xiaolei Du, \$ Dawei Yin, $\$$ Zemei Ge, Xin Wang* and Runtao Li (iD *
}

The efficient asymmetric Michael addition reactions of pyrrolones with chalcones catalyzed by a simple and commercially available chiral 1,2-diaminocyclohexane-2-(N-Boc-amino)benzoic acid have been developed to provide the corresponding Michael adducts in good yields (up to 90\%) and high enantioselectivities (up to $95 \%$ ee).
Pyrrolones are privileged heterocyclic scaffolds found in a number of natural and synthetic molecules (Fig. 1), ${ }^{1}$ which are reported to possess important pharmacological activities, especially antibacterial and antifungal, ${ }^{2}$ anti-tubercular, ${ }^{3}$ anticonvulsant activity, ${ }^{4}$ immunosuppressive activity, ${ }^{5}$ anticancer activity, ${ }^{6}$ analgesic and anti-inflammatory activity. ${ }^{7}$ Additionally, optical pyrrolones can act as synthetic precursors of some natural products. ${ }^{8}$ In particular, chiral 5 -substituted pyrrolones and their derivatives display marvelous biological properties, ${ }^{9}$ which undoubtably increase their importance both in chemical synthesis and synthetic methodologies. Therefore, the exploration of asymmetric reactions from readily available starting material pyrrolones to their 5-substituted derivatives has recently appeared extremely attractive.

In general, these asymmetric reactions include asymmetric Michael addition reaction, asymmetric Aldol condensation reaction and asymmetric Mannich reaction. ${ }^{10}$ Recently, some secondary and tertiary amines, such as proline and its derivatives, thioureas, quinines and cinchona alkaloids were reported to catalyze above asymmetric reactions. ${ }^{11}$ Great improvement



(+)-lactacystin

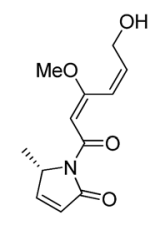

Palmyrrolinone

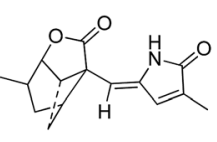

(+)-Isoampullicin
Fig. 1 Representative compounds containing pyrrolone scaffold

State Key Laboratory of Natural and Biomimetic Drugs, School of Pharmaceutical Science, Peking University, Beijing 100191, China. E-mail: xinwang@bjmu.edu.cn; lirt@bjmu.edu.cn

$\dagger$ Electronic supplementary information (ESI) available. See DOI: 10.1039/c7ra03069j

\$ These authors contributed equally to the work. has been made in asymmetric Michael addition reaction (Fig. 2). For example, Chen and co-workers achieved satisfied results in the enantio- and diastereoselective Michael reaction of $N$-Boc pyrrolone with $\alpha, \beta$-unsaturated aldehydes catalyzed by proline, ${ }^{12}$ Feng's group developed a novel guanidine combining with secondary amine as bifunctional catalysts for the asymmetric Michael reaction of $N$-Boc pyrrolone with malonates. ${ }^{13}$ However, to the best of our knowledge, chiral primary amine has rarely been used to the 5 -deprotonation of pyrrolone pathway, ${ }^{14}$ and the poor reactive chalcones have never been reported to proceed asymmetric Michael reaction with pyrrolones. So it still represents a challenging task regarding the reactivity and stereoselectivity of the two relatively inert reactants.

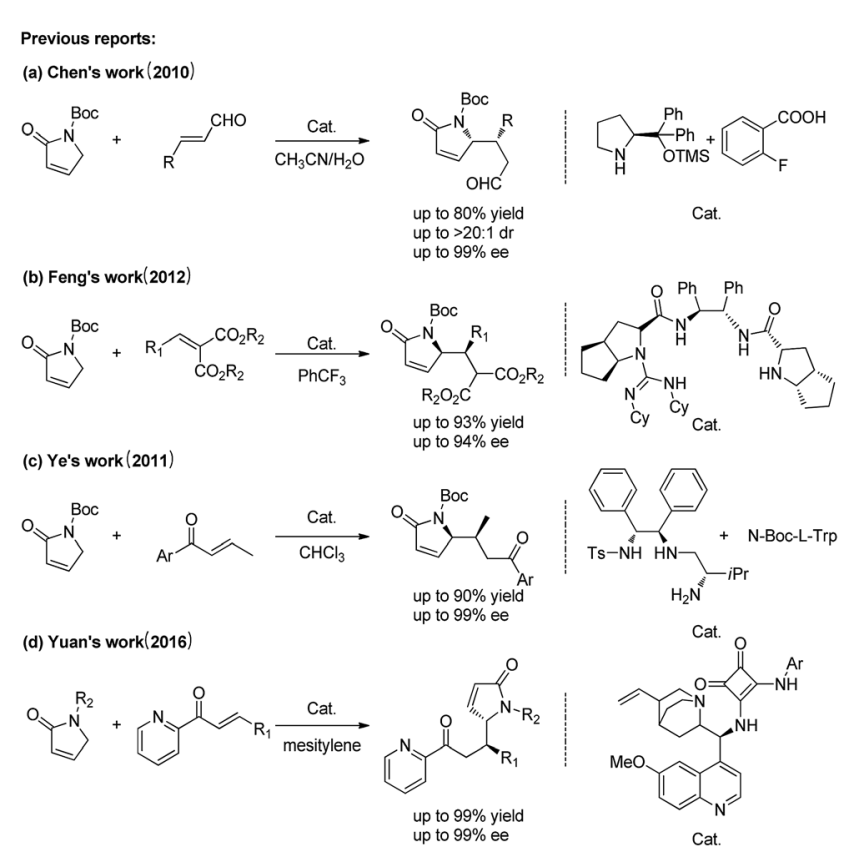

Fig. 2 Asymmetric Michael addition reactions of pyrrolones reported previously. 
In our previous report, we have successfully realized the asymmetric Michael addition reactions of furanones with chalcones using simple chiral primary-diamine salts (Scheme 1). ${ }^{15}$ As an extension of our work, herein, we wish to disclose an efficient asymmetric Michael addition reaction of pyrrolones with chalcones catalyzed by chiral primary-diamine salts (Table 1 ).

Our initial investigation began with the reaction of 4-phenyl $N$-benzyl pyrrolone (1a) and chalcone (2a) using chiral (1R, 2R)cyclohexane-1,2-diamine (C1, $20 \mathrm{~mol} \%)$ as catalyst and acetic

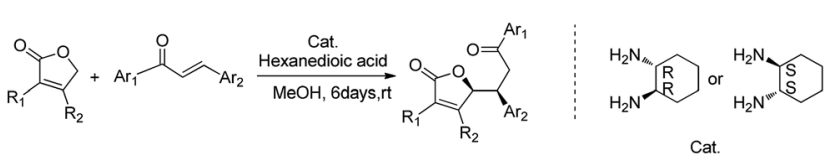

Scheme 1 Organocatalyzed direct Michael addition reactions of furanones to chalcones.

Table 1 Optimization of reaction conditions ${ }^{a}$

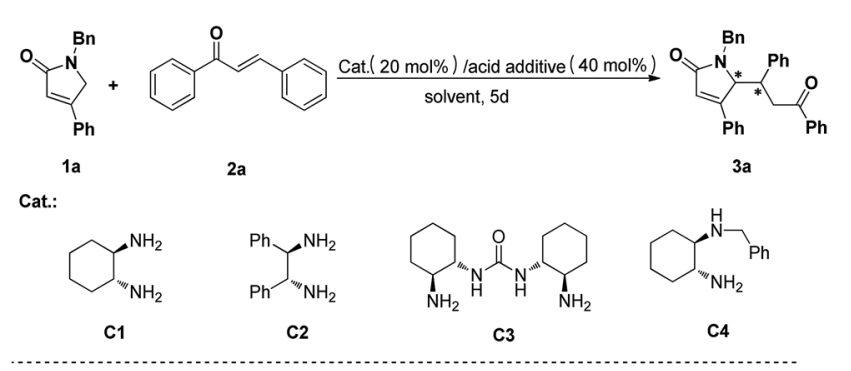

additive:
$\mathrm{CH}_{3} \mathrm{COOH}$

A1
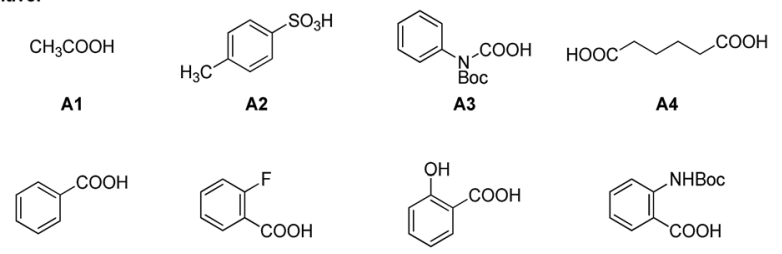

A5
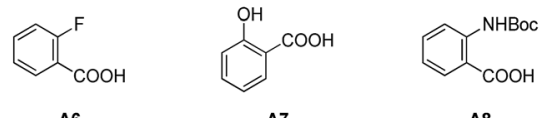

A6

A8

\begin{tabular}{|c|c|c|c|c|c|c|c|}
\hline Entry & Cat. & Solvent & Additive & $\begin{array}{l}\mathrm{T} \\
\left({ }^{\circ} \mathrm{C}\right)\end{array}$ & $\begin{array}{l}\text { Yield }^{b} \\
(\%)\end{array}$ & $\mathrm{dr}^{c}$ & $\begin{array}{l}\mathrm{ee}^{d} \\
(\%)\end{array}$ \\
\hline 1 & C1 & $\mathrm{MeOH}$ & $\mathbf{A 1}$ & r.t. & 25 & $8: 1$ & 89 \\
\hline 2 & $\mathrm{C} 2$ & $\mathrm{MeOH}$ & $\mathbf{A 1}$ & r.t. & Trace & - & - \\
\hline 3 & C3 & $\mathrm{MeOH}$ & $\mathbf{A 1}$ & r.t. & 0 & - & - \\
\hline 4 & $\mathrm{C4}$ & $\mathrm{MeOH}$ & $\mathbf{A 1}$ & r.t. & Trace & - & - \\
\hline 5 & C1 & $\mathrm{MeOH}$ & A2 & r.t. & 0 & - & - \\
\hline 6 & C1 & $\mathrm{MeOH}$ & A3 & r.t. & 20 & $12: 1$ & 93 \\
\hline 7 & C1 & $\mathrm{MeOH}$ & $\mathbf{A 4}$ & r.t. & 25 & $18: 1$ & 91 \\
\hline 8 & C1 & $\mathrm{MeOH}$ & A5 & r.t. & 27 & $10: 1$ & 94 \\
\hline 9 & C1 & $\mathrm{MeOH}$ & A5 & 40 & 45 & $1: 1$ & 55 \\
\hline 11 & C1 & $\mathrm{EtOH}$ & A5 & 40 & 30 & $2: 1$ & 85 \\
\hline 12 & C1 & PhMe & A5 & 40 & 48 & $1: 1$ & 90 \\
\hline 13 & C1 & PhMe & A6 & 40 & 50 & $3: 1$ & 91 \\
\hline 14 & C1 & PhMe & A7 & 40 & 80 & $1: 1$ & 80 \\
\hline 15 & C1 & PhMe & A8 & 40 & 65 & $3: 2$ & 95 \\
\hline
\end{tabular}

${ }^{a}$ All reactions were carried out using 1.0 equiv. of $1 \mathrm{a}(0.15 \mathrm{mmol}), 1.5$ equiv. of $2 \mathrm{a}(0.225 \mathrm{mmol})$, and $20 \mathrm{~mol} \%$ of catalyst $(0.03 \mathrm{mmol}), 40$ mol $\%$ of additive $(0.06 \mathrm{mmol}) .{ }^{b}$ Isolated yield. ${ }^{c}$ Determined by NMR. ${ }^{d}$ Determined by chiral HPLC analysis. acid (A1, $40 \mathrm{~mol} \%)$ as additive in methanol at room temperature, and the desired product 3a was obtained in 25\% yield with $8: 1$ dr and $89 \%$ ee (Table 1, entry 1). Encouraged by this result, we began the further optimization as follows. Firstly, different chiral primary amine catalysts were screened (Table 1, entries 1-4) and C1 still was the best one. Then, the effect of the additive on the reaction was tested (Table 1 , entries 5-8). It can been seen that all selected additives except A2 worked well and A5 is better by comparison (Table 1, entry 8). By raising the reaction temperature from r.t. to $40{ }^{\circ} \mathrm{C}$, the yield of $3 \mathrm{a}$ was improved to $45 \%$, unfortunately, its stereoselectivity was significantly decreased (Table 1, entry 9). Furtherly, solvent screening revealed that compound 3a could be obtained in $48 \%$ yield with $90 \%$ ee in toluene at $40{ }^{\circ} \mathrm{C}$ (Table 1, entry 12). In order to further optimize the yield and stereoselectivity, the derivatives of benzoic acid (A6-A8) were examined (Table 1, entries 13-15). The results revealed that, using $\mathbf{C 1}$ as catalyst and $\mathbf{A 8}$ as additive, the reaction between substrates $1 \mathrm{a}$ and $2 \mathrm{a}$ in toluene at $40{ }^{\circ} \mathrm{C}$ gave the desired product $3 \mathrm{a}$ in $65 \%$ yield, $3: 2 \mathrm{dr}$ and $95 \%$ ee (Table 2 , entry 15 ).

With the optimized conditions in hand, the application scope of the catalytic system was then explored. As shown in Table 2, different 4-aromatic ring substituted $N$-benzyl pyrrolones react well with variety of chalcones giving the corresponding products 3 in moderate to good yields and high enantioselectivities. For $N$-benzyl pyrrolones (Table 2, entries 1$3)$, the electron nature of the substituents on the aromatic ring at the 4-position of $\mathrm{N}$-benzyl pyrrolones (1) did not have an

Table 2 Substrate scope for the Michael addition reaction of 1 and $2^{a}$



\begin{tabular}{|c|c|c|c|c|c|c|}
\hline Entry & 1 & $\mathrm{Ar}_{2}$ & $\mathrm{Ar}_{3}$ & $\begin{array}{l}3 / \text { yield }^{b} \\
(\%)\end{array}$ & $\begin{array}{l}\text { dr syn : } \\
\text { anti }^{c}\end{array}$ & $\begin{array}{l}\text { ee } \\
(\%)(s y n)^{d}\end{array}$ \\
\hline 1 & 1a & $\mathrm{Ph}$ & $\mathrm{Ph}$ & $3 a / 65$ & $3: 2$ & 95 \\
\hline 2 & 1b & $\mathrm{Ph}$ & $\mathrm{Ph}$ & $3 \mathbf{b} / 40$ & $2.5: 1$ & 90 \\
\hline 3 & $1 \mathrm{c}$ & $\mathrm{Ph}$ & $\mathrm{Ph}$ & $3 \mathbf{c} / 60$ & $2: 1$ & 90 \\
\hline 4 & 1a & $\mathrm{Ph}$ & $3-\mathrm{MeOC}_{6} \mathrm{H}_{4}$ & $3 \mathbf{d} / 70$ & $4: 3$ & 90 \\
\hline 5 & 1a & $\mathrm{Ph}$ & $4-\mathrm{ClC}_{6} \mathrm{H}_{4}$ & $3 e / 62$ & $2: 1$ & 81 \\
\hline 6 & 1a & $\mathrm{Ph}$ & $3-\mathrm{NO}_{2} \mathrm{C}_{6} \mathrm{H}_{4}$ & $3 \mathbf{f} / 75$ & $2: 1$ & 92 \\
\hline 7 & $1 \mathrm{c}$ & $\mathrm{Ph}$ & $3-\mathrm{MeOC}_{6} \mathrm{H}_{4}$ & $3 g / 64$ & $3: 1$ & 93 \\
\hline 8 & 1c & $\mathrm{Ph}$ & $3-\mathrm{MeC}_{6} \mathrm{H}_{4}$ & $3 \mathrm{~h} / 55$ & $5: 3$ & 85 \\
\hline 9 & 1c & $\mathrm{Ph}$ & $4-\mathrm{MeC}_{6} \mathrm{H}_{4}$ & $3 \mathbf{i} / 60$ & $2.5: 1$ & 85 \\
\hline 10 & 1c & $\mathrm{Ph}$ & $3-\mathrm{ClC}_{6} \mathrm{H}_{4}$ & $3 \mathbf{j} / 82$ & $2: 1$ & 83 \\
\hline 11 & 1c & $\mathrm{Ph}$ & $4-\mathrm{ClC}_{6} \mathrm{H}_{4}$ & $3 \mathbf{k} / 64$ & $2: 1$ & 87 \\
\hline 12 & $1 \mathrm{c}$ & $\mathrm{Ph}$ & $4-\mathrm{FC}_{6} \mathrm{H}_{4}$ & $31 / 55$ & $2: 1$ & 85 \\
\hline 13 & 1c & $4-\mathrm{MeC}_{6} \mathrm{H}_{4}$ & $\mathrm{Ph}$ & $3 \mathbf{m} / 69$ & $5: 4$ & 84 \\
\hline 14 & 1c & $4-\mathrm{MeC}_{6} \mathrm{H}_{4}$ & $3-\mathrm{MeC}_{6} \mathrm{H}_{4}$ & $3 n / 66$ & $1: 1$ & 85 \\
\hline 15 & $1 \mathrm{c}$ & $4-\mathrm{MeC}_{6} \mathrm{H}_{4}$ & $3-\mathrm{BrC}_{6} \mathrm{H}_{4}$ & $30 / 64$ & $2.5: 1$ & 86 \\
\hline 16 & 1c & $4-\mathrm{MeC}_{6} \mathrm{H}_{4}$ & $4-\mathrm{FC}_{6} \mathrm{H}_{4}$ & $3 \mathbf{p} / 90$ & $1: 1$ & 87 \\
\hline
\end{tabular}

${ }^{a}$ All reactions were carried out using 1.0 equiv. of $1 \mathrm{a}(0.15 \mathrm{mmol}), 1.5$ equiv. of $2 \mathrm{a}(0.225 \mathrm{mmol})$, and $20 \mathrm{~mol} \%$ of catalyst $(0.03 \mathrm{mmol}), 40$ mol\% of additive $(0.06 \mathrm{mmol}) .{ }^{b}$ Isolated yield. ${ }^{c}$ Determined by NMR. ${ }^{d}$ Determined by chiral HPLC analysis. 


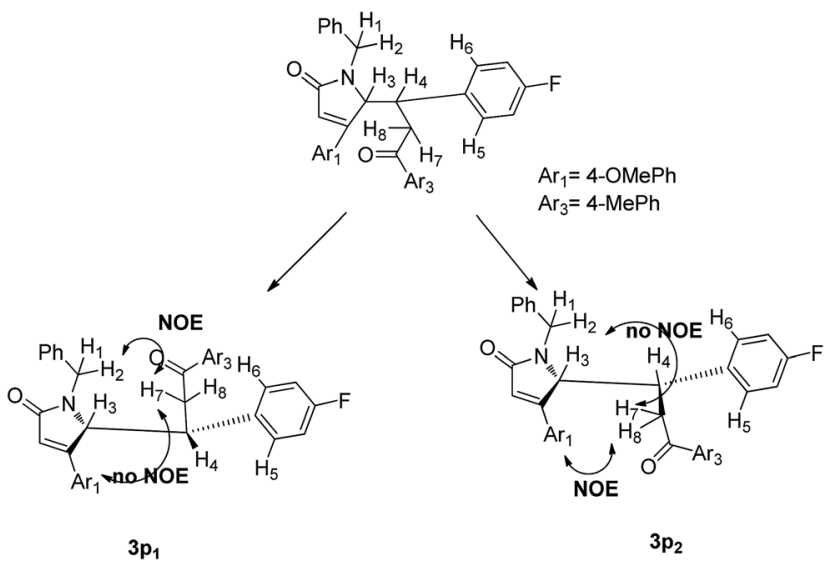

Fig. 3 NOESY analysis of product 3p.

obvious effect on either diastereoselectivity or enantioselectivity when ignoring the fact that 4-bromo substituent decreased the yield (Table 2, entry 2). As regards chalcones, whatever their aromatic rings $\mathrm{Ar}_{2}$ or $\mathrm{Ar}_{3}$ contained electron-rich or electrondeficient substituents, the reaction remained stable yields and high enantioselectivities.

NOESY experiments performed on compound $3 \mathbf{p},{ }^{\mathbf{1 6}}$ revealed strong correlations between hydrogen 2 and $5,6,7,8$ on $3 \mathbf{p}_{\mathbf{1}}$, and no correlations between the hydrogens on $\mathrm{Ar}_{1}$ and hydrogen 7 . As for $\mathbf{3} \mathbf{p}_{2}$, on the contrary, there were strong correlations between the hydrogens on $\mathrm{Ar}_{1}$, hydrogen 7 , but no correlations between hydrogen 2 and 7, 8. Thus, the NOESY experiments allowed us to confirm the relative configuration of product 3p (Fig. 3). (see ESI $\dagger$ ). Unfortunately, we were unable to grow quality crystals to determine compound 3p's absolute configuration.

\section{Conclusions}

In conclusion, we have developed an efficient asymmetric Michael addition reaction of 4-aromatic ring substituted $\mathrm{N}$ benzyl pyrrolones with chalcones utilizing the simple and commercially available chiral 1,2-diaminocyclohexane-2-( $N$ Boc-amino)benzoic acid as the cooperative catalysts. The corresponding Michael addition products were obtained in moderate to good yields (up to 90\%) and excellent enantioselectivity (up to $95 \%$ ee). Further studies and applications of vicinal primary diamine as catalyst in asymmetric reactions are currently underway in our laboratory.

\section{Acknowledgements}

We are grateful for the financial support from the National Natural Science Foundation of China (no. 81673287).

\section{Notes and references}

1 (a) K. C. Nicolaou, S. M. Dalby and U. Majumder, J. Am. Chem. Soc., 2008, 130, 14942-14943; (b) P. Magnus, T. Katoh, I. R. Matthews and J. C. Huffman, J. Am. Chem.
Soc., 1989, 111, 6707-6711; (c) S. E. Denmark, Y. C. Moon and C. B. W. Senanayake, J. Am. Chem. Soc., 1990, 112, 311-315.

2 A. Husain, M. S. Y. Khan, S. M. Hasan and M. M. Alam, Eur. J. Med. Chem., 2005, 40, 1394-1404.

3 (a) A. Husain, S. M. Hasan, S. Lal and M. M. Alam, Indian J. Pharm. Sci., 2006, 68, 536-538; (b) A. Ahmad, A. Husain, S. A. Khan, M. Mujeeb and A. Bhandari, J. Saudi Chem. Soc., 2015, 19, 340-346.

4 C. Grunwald, C. Rundfeldt, H. J. Lankau, T. Arnold, N. Hofgen, R. Dost, U. Egerland, H. J. Hofmann and K. Unverferth, J. Med. Chem., 2006, 49, 1855-1866.

5 R. D. Alessio, A. Bargiotti, O. Carlini, F. Colotta, M. Ferrari, P. Gnocchi, A. Isetta, N. Mongelli, P. Motta, A. Rossi, M. Rossi, M. Tibolla and E. Vanotti, J. Med. Chem., 2000, 43, 2557-2565.

6 M. M. Alam, A. Husain, S. M. Hasan and T. Anwer, Eur. J. Med. Chem., 2009, 44, 2636-2642.

7 S. Olla, F. Manetti, E. Crespan, G. Maga, A. Angelucci, S. Schenone, M. Bologna and M. Botta, Bioorg. Med. Chem. Lett., 2009, 19, 1512-1516.

8 (a) G. R. Pettit, S. Freeman, M. J. Simpson, M. A. Thompson, M. R. Boyd, M. D. Williams, G. R. Pettit and D. L. Doubek, Anti-Cancer Drug Des., 1995, 10, 243-249; (b) K. Sakata, K. Aoki, C. F. Chang, A. Sakurai, S. Tamura and S. Murakoshi, Agric. Biol. Chem., 1978, 42, 457-459; (c) M. Tereda, M. Sano, A. I. Ishii, H. Kino, S. Fukushima and T. J. Noro, J. Pharm. Soc. Jpn., 1982, 79, 93-98; (d) H. Shinozaki and M. Ishida, Brain Res., 1985, 334, 33-40; (e) D. Li, Y. J. Wang, L. Q. Wang, J. Wang, P. X. Wang, K. Z. Wang, L. Liu, D. S. Liu, X. X. Jiang and D. X. Yang, Chem. Commun., 2016, 52, 9640-9643.

9 (a) L. Lin, J. Zhang, X. Ma, X. Fu and R. Wang, Org. Lett., 2011, 13, 6410-6413; (b) J. Zhang, X. Liu, X. Ma and R. Wang, Chem. Commun., 2013, 49, 9329-9331; (c) C. Curti, B. Ranieri, L. Battistini, G. Rassu, V. Zambrano, G. Pelosi, G. Casiraghi and F. Zanardi, Adv. Synth. Catal., 2010, 352, 2011-2022; (d) N. E. Shepherd, H. Tanabe, Y. Xu, S. Matsunaga and M. Shibasaki, J. Am. Chem. Soc., 2010, 132, 3666-3667.

10 (a) A. R. Choudhury and S. Mukherjee, Org. Biomol. Chem., 2012, 10, 7313-7320; (b) Y. Chen, U. Das, M. Liu and W. Lin, J. Org. Chem., 2015, 80, 1985-1992; (c) J. L. Zhang, X. H. Liu, X. J. Ma and R. Wang, Chem. Commun., 2013, 49, 3300-3302; (d) J. L. Zhang, X. H. Liu, X. J. Ma and R. Wang, Chem. Commun., 2013, 49, 9329-9331; (e) Y. Zhang, Y. L. Shao, H. S. Xu and W. Wang, J. Org. Chem., 2011, 76, 1472-1474; (f) T. Y. Liu, H. L. Cui, J. Long, B. J. Li, Y. Wu, L. S. Ding and Y. C. Chen, J. Am. Chem. Soc., 2007, 129, 1878-1879; $(g)$ N. E. Shepherd, H. Tanabe, Y. J. Xu, S. Matsunaga and M. Shibasaki, J. Am. Chem. Soc., 2010, 132, 3666-3667; (h) J. T. Li, S. Qiu, X. Y. Ye, B. Zhu, H. J. Liu and Z. Y. Jiang, J. Org. Chem., 2016, 81, 1191611923; (i) H. Tanabe, Y. J. Xu, B. Sun, S. Matsunaga and M. Shibasaki, Heterocycles, 2012, 86, 611-622; (j) S. G. Zlotin and S. V. Kochetkov, Russ. Chem. Rev., 2015, 84, 1077-1099; (k) J. C. Kizirian, Chem. Rev., 2008, 108, 
140-205; (l) Y. H. Lam, M. N. Grayson, M. C. Holland, A. Simon and K. N. Houk, Acc. Chem. Res., 2016, 49, 750-762. 11 (a) W. Wu, X. Li, H. C. Huang, X. Q. Yuan, J. Z. Lu, K. L. Zhu and J. X. Ye, Angew. Chem., Int. Ed., 2013, 52, 1743-1747; (b) J. W. Xie, L. Yue, D. Xue, X. L. Ma, Y. C. Chen, Y. Wu, J. Zhu and J. G. Deng, Chem. Commun., 2006, 48, 1563-1565; (c) T. B. Poulsen, C. Alemparte and K. A. Jørgensen, J. Am. Chem. Soc., 2005, 127, 11614-11615; (d) P. I. Dalko and L. Moisan, Angew. Chem., Int. Ed., 2001, 40, 3726-3748; (e) J. L. Zhang, X. H. Liu, X. J. Ma and R. Wang, Chem. Commun., 2013, 49, 3300-3302.
12 X. Feng, H. Cui, S. Xu, L. Wu and Y. Chen, Chem.-Eur. J., 2010, 16, 10309-10312.

13 Y. Yang, S. Dong, X. Liu, L. Lin and X. Feng, Chem. Commun., 2012, 48, 5040-5042.

14 H. Huang, Z. Jin, K. Zhu, X. Liang and J. Ye, Angew. Chem., Int. Ed., 2011, 50, 3232-3235.

15 J. F. Wang, C. Qi, Z. M. Ge, T. M. Cheng and R. T. Li, Chem. Commun., 2010, 46, 2124-2126.

16 G. Chaubet, T. Coursindel, X. Morelli, S. Betzi, P. Roche, Y. Guari, A. Lebrun, L. Toupet, Y. Collette, I. Parrot and J. Martinez, Org. Biomol. Chem., 2013, 11, 4719-4726. 